\title{
Diet selection and animal state: an integrative framework
}

\author{
Ilias Kyriazakis*, Bert J. Tolkamp and Gerry Emmans \\ Animal Biology Division, Scottish Agricultural College, King's Buildings, West Mains Road, Edinburgh EH9 3JG, UK
}

\begin{abstract}
In the present paper we deal with the problems of explaining and predicting diet selection of animals under controlled conditions, i.e. conditions that can be described and in which any influences of the environment can be either controlled or at least monitored. Diet selection is considered within an integrative framework of feeding behaviour that views both food intake and diet selection as an outcome of the animal's internal state and knowledge of the feeding environment. Three questions that arise from the framework are considered: (1) how do animals learn about foods available to them as a choice? (2) what changes in internal state affect diet selection? (3) how much time is needed for a change in the animal's internal state to be detected and for it to react to this change through a modification of its diet selection? It is proposed that animals have developed behavioural mechanisms that allow them to recognize foods on the basis of their nutritional as well as other properties. The rate at which animals learn about foods depends largely on the extent of the animal's deficiency and on the extent of the post-ingestive consequences induced by the foods. There is little evidence that animals modify their diet selection in response to short-term systemic fluctuation of their internal environment. On the other hand, long-term changes in the internal state of the animal lead to consequent long-term changes in diet selection. The time needed for a change in diet selection to be observed depends on the deviation created in the animal's internal state, either as a result of a physiological change or as a consequence of feeding. Thus, a more appropriate question to consider is not 'what time period matters to the animal?' but 'how much change or deviation in the internal state is the animal prepared to accept?'
\end{abstract}

Internal state: Diet selection: Feeding behaviour: Learning

In natural environments the availability and composition of foods varies both spatially and temporally, and the feeding behaviour of the animal will be influenced by environmental and social factors. The animal is expected to select a diet consistent with adaptive behaviour and, hence, that which is suited to its needs. Studies of the feeding behaviour of animals in natural environments concentrate on describing what the animal chooses to eat when it forages and has access to foods that are a part of its natural feeding repertoire. It is very difficult to describe sufficiently the feeding, social and thermal environments in nature (Emmans, 1991) and, therefore, it is difficult to either account for or predict diet selection under such conditions. The study of diet selection in natural environments then becomes natural history with an emphasis on description. The difficulties raised by the possible complexity of natural environments have led workers in the field to deal with the diet selection of animals that either have a narrow feeding repertoire (i.e. specialist animals), or have simplified foods which differ in a single nutritional dimension (Krebs \& McCleery, 1984). The prediction of diet selection in natural environments remains a challenge. Whether or not human subjects in their current environments are seen as being in natural environments, it is still the case that much of the work on diet selection in human subjects is descriptive.

Diet selection can also be studied under more controlled environmental conditions in the laboratory, where animals are given access to few foods whose composition can be adequately described. The assumption made in such studies is that even under such partly artificial conditions the diets selected will follow from the general adaptive nature of the animal's feeding behaviour (Siegel, 1993). The behaviour under such conditions has been called 'preferred diet selection', since it is the feeding behaviour shown by the animal when 'constraints' arising from the environment are removed (Nielsen, 1999). This behaviour forms the starting point from which various controlled modifications of the environment, including the feeding environment, can be

Abbreviations: MP, metabolizable protein; RDP, rumen-degradable protein.

*Corresponding author: Dr Ilias Kyriazakis, fax +44 (0)131 535 3121, email i.kyriazakis@ed.sac.ac.uk 
imposed in order to investigate which features and variables matter, and how they influence diet selection. This approach has been applied with a considerable degree of success (for example, see Simpson \& Ludlow, 1986; Kyriazakis \& Emmans, 1992; Hutchings et al. 1999) to develop frameworks of feeding behaviour which allow diet selection to be both explained and predicted. Any 'rules of diet selection' which emerge from such work are expected to be general, to be characteristic of the animal in the same way as its physiology is characteristic, and to apply in more complex natural environments. These rules can be helpful in taking forward the analysis of the data collected in such environments.

In a symposium that deals with the 'Social and environmental influences on diet choices' it is fitting to consider diet selection in non-natural environments and to attempt to define rules that might apply more generally. The papers that will follow will be dealing essentially with how various factors influence and modify diet selection. We are working within the context of the framework of feeding behaviour described by Kyriazakis (1997). The framework has been developed to account for the feeding behaviour of domestic and farm animals, with the goal of arriving at quantitative predictions of food intake and diet selection. A brief description of the framework forms the first part of the present paper. We see it as being capable of extension to other kinds of animal and to natural environments, although we have not done so here. In the remainder of the paper we consider its application to the specific problems of internal state, learning and timescales.

\section{A framework of feeding behaviour}

The framework shown schematically in Fig. 1 considers feeding behaviour as part of a continuous close-looped system. Feeding behaviour, both in terms of food intake and diet selection, influences, and is in turn influenced by, an animal's internal state and knowledge of its feeding

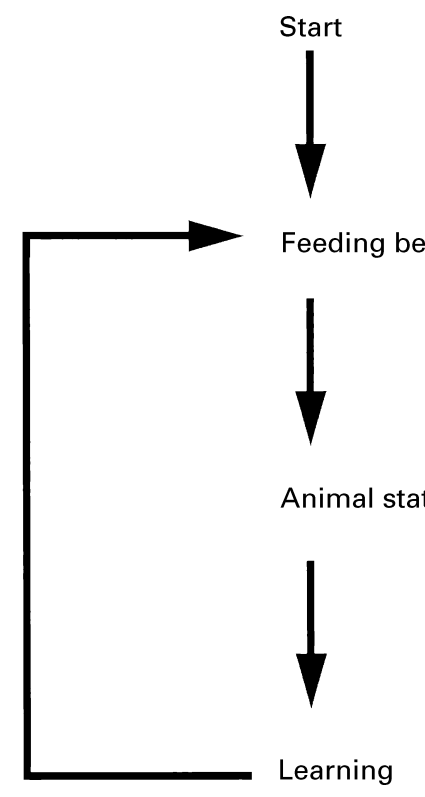

Fig. 1. A framework for considering the way in which learning and the animal's internal state affect feeding behaviour. environment. The starting point in time of feeding behaviour of all animals arises from some 'hard-wired' elements. Examples are the action of sucking in mammals and pecking in birds, which result initially in the ingestion of both 'food' and 'non-food' items. Since it is only the consumption of food that leads to a change in internal state, the animal is expected to learn very quickly to differentiate between that which is food and that which is not. The sequence of events shown in Fig. 1 would be expected to lead to a stable or habitual feeding behaviour which should be maintained over time. Apart from any other advantages it will be expected to lead to the choosing of diets that are safe. The repetitive nature of sucking behaviour of young mammals could be seen as the outcome of this sequence.

The internal state of an animal, however, is not static but dynamic. It is the outcome of physiological changes, such as those accompanying growth and pregnancy, and the direct effects of past or current feeding. On the reasonable assumption that the animal is trying to achieve something through its feeding behaviour, the expectation is that any changes for the worse in its internal state will be followed by an appropriate modification of its feeding behaviour. For an animal that feeds on more than one food, it might also be necessary to include new foods in its diet and hence learn about them by the changes in its state that they produce, and to the temporal and spatial changes that occur in its feeding environment. The consequence then is that the loop of Fig. 1 will be repeated as many times as, and whenever, necessary during the animal's lifetime.

Kyriazakis (1997) applied this framework to problems of diet selection in domestic animals, including young chicks and cows, with some success. Questions that arise for the problem of diet selection are: (1) how do animals learn about the foods available as a choice? (2) which changes in internal state affect diet selection? (3) how much time is needed for there to be a change in the internal state of the animal that it can recognize and react to it through a modification of its diet selection? These questions, and possible answers to them, will now be considered in turn.

\section{Learning about foods}

The framework described earlier suggests that the feeding behaviour of animals will depend largely on learning, since learning would make the animal more effective in adapting to the temporal and spatial changes in its feeding environment. This suggestion does not conflict with the fact that there are 'hard-wired' elements of feeding behaviour, but in many cases these elements are only a small part of the repertoire of feeding. It is now generally accepted that animals have developed behavioural mechanisms to allow them to recognize foods on the basis of their nutritional as well as other properties, and to include foods in their diet according to the post-ingestive consequences that they have. One such behavioural mechanism is the development of conditioned associations between the organoleptic and the nutritional properties of foods. Certain organoleptic properties are more effective in leading to conditioned responses than others, such as the flavour or taste of the food in mammals and the colour of the food in birds (Forbes \& Kyriazakis, 1995). There is good evidence in the literature 
for both the development of conditioned preferences for foods that are associated with positive post-ingestive consequences as a result of intake of nutrients (for example, see Arsenos \& Kyriazakis, 1999), and for the conditioned aversions towards foods that are associated with toxic consequences (for example, see Kyriazakis et al. 1998). Ralphs et al. (1999) present a more detailed account of the development and significance of conditioned responses in animals.

The suggestion that an animal needs to learn about the consequences of eating a food in order to include it in its diet appears to be at odds with examples of 'specific appetites' in the literature. Among these specific appetites are an appetite for $\mathrm{NaCl}$ in rats (Denton, 1982) and for $\mathrm{Ca}$ in laying hens (Hughes, 1979). It is suggested that animals previously deprived of a nutrient are able to select almost instantaneously a food supplemented with the nutrient without any previous experience of that supplemented food (for example, see Hughes, 1979; Denton, 1982; Blair-West et al. 1992). This proposal has led some researchers to suggest that animals are equipped with a set of appetites for many specific nutrients that enable them to select an appropriate diet almost instantaneously (Deutsch et al. 1989), and that this is the normal way animals choose a diet. The proposal that there are many specific appetites with these properties can be questioned. Animals have a requirement for a large number of nutrients (about twelve each of amino acids, vitamins and mineral elements) in their diet. With so many nutrients it seems to us to be unlikely that evolution would have equipped them with a specific appetite for every single nutrient; this would seem to be a rather wasteful strategy. However, it does not mean that there are no specific appetites, only that it is not the normal means by which an animal selects its diet.

The speed of learning is likely to depend on the extent to which the previous disturbance has affected the animal's internal state. The greater the departure from the appropriate internal state the greater will be the reinforcing properties of the food and the faster the learning. Animals that have been greatly deprived of a nutrient can be expected to select very rapidly the supplemented food or appropriate diet, since under these circumstances the reinforcing properties of feeding can be very rapid indeed (Capaldi et al. 1991). The effects may be similar to the reinforcement human subjects derive from drinking after a period of water deprivation (Blair-West et al. 1992). This explanation seems to account adequately for the way in which animals learn about their foods.

A further issue is the duration of the persistence of learned feeding behaviour in the absence of continuous reinforcement. There is disagreement about the length of time for which learning does persist, and about whether or not highly persistent behaviour is beneficial. The view has been put forward that animals such as young ruminants are able to remember whether foods had positive or negative post-ingestive consequences for at least 1-3 years, with no intervening exposure to these foods (for example, see Kendrick, 1992). In other instances, also in young ruminants, learned food associations are extinguished within 1 week (for example, see Kyriazakis et al. 1998). We propose that the persistence of learned associations will increase with the extent to which the post-ingestive consequences associated with the organoleptic property are harmful. Within the 'normal' foraging behaviour the animal's learned associations should have a flexible occurrence, and hence be easy to extinguish. This outcome would have an adaptive significance, given the temporal and spatial variability in nutrient and toxin concentrations of foods. It is concluded, therefore, that the rate at which animals learn about foods and the period during which this association is retained depends largely on the extent of the animal's deficiency and on the extent of the post-ingestive consequences they induce.

\section{The role of internal state}

\section{Internal state and changes in it}

The state of the animal will include the levels of many metabolites and hormones as well as such variables as body temperature and the levels of protein and lipid stores. In ruminants the levels of $\mathrm{pH}$ and $\mathrm{NH}_{3}$ in the rumen fluid can be considered as state variables. State will also include the animal's extent of maturity and the various phases of its reproductive cycle. A complete description of state is likely to be complex. However, in order to predict diet selection in a given case, a description in terms of only a few variables may be sufficient.

There are two kinds of changes that can be considered to occur in an animal's internal state. The first are the shortterm, often systemic, fluctuations that occur in the levels of metabolites or hormones during the day. These fluctuations can be the direct consequence of the action of feeding or the consequence of events unrelated to feeding. The second kind of change is that which occurs in the longer-term and reflects physiological changes as the animal grows or moves through the various phases of its reproductive cycle. Given the framework we expect that such changes in the internal state will be reflected in changes in diet selection. The question then is whether shorter- or longer-term changes, or both, lead to direct modifications of diet selection.

\section{The role of internal state in diet selection}

It is widely recognized that animals are equipped with mechanisms to enable them to detect changes in their internal state as a consequence of food ingestion, and hence to modify their feeding behaviour. There is disagreement about the quantity of food that is needed to produce sufficient change in internal state to cause a consequent change in diet selection. It has been suggested (Provenza et al. 1998) that the short-term systemic fluctuations in the levels of metabolites and hormones that occur during a meal are sufficient to affect the composition of the next meal to be selected. But the evidence cited in favour of this view, which is that of de Jong (1981), is precisely that which refutes the argument. In the work of de Jong (1981) the short-term systemic fluctuations that occurred during a meal appeared to relate very little, if at all, to modifications of feeding behaviour. In the short-term, feeding behaviour, and diet selection in particular, is the means by which animals exploit very effectively their feeding environment. It is 
characterized by a great extent of flexibility, as will be shown later.

On the other hand, there seems to be very strong evidence that long-term changes in the internal state of the animal lead to consequent long-term changes in their diet selection. Examples are: the degree of maturity (Bradford \& Gous, 1991; Shariatmadari \& Forbes, 1992; Kyriazakis et al. 1993); the degree of fatness (Kyriazakis \& Emmans, 1991); pregnancy and lactation (Cooper et al. 1994); the onset of egg production (Classen \& Scott, 1982); disease (gastrointestinal parasitism in sheep; Kyriazakis et al. 1994). In our laboratory we have investigated the longer-term effects of the internal state of animal on the choices that it makes between two foods that differ in their content of one nutrient, mainly protein. This study was done partly with the view to arriving at measurements of the protein needs of animals at different physiological stages. The evidence from non-ruminant farm animals is consistent with the view that they are able to select a diet which is a reflection of their protein needs, whilst at the same time they avoid an excess protein intake. The evidence from ruminant animals, however, did not always seem to be consistent with this view.

When lactating cows were offered a choice between two foods that differed in their metabolizable protein (MP) yield for a period of up to 40 weeks, they selected a diet which, although it was consistently different from random selection, did not change systematically through lactation (Tolkamp et al. 1998a). This choice was made despite the fact that the presumed protein requirement fell. Even within cows diet selection was not significantly related either to stage of lactation or to milk protein output at different times. There was no significant correlation between the diet selection and the milk protein output across individuals. The initial interpretation of these experiments was that ruminants, unlike non-ruminant animals, are unable to select a diet that reflects the changes in their (protein) internal state throughout lactation. However, since we strongly hold the view that feeding behaviour is adaptive for all animals, irrespective of differences in their digestive system or the environment in which they are kept, we persevered with the view that the observed diet selection was somehow a reflection of their needs.

One of the alternative hypotheses tested was that the cows in our experiment were not selecting a diet on the basis of their MP yields, but rather on the basis of their rumendegradable protein (RDP) contents. Ruminant animals depend largely on the production of protein from RDP by their rumen micro-organisms. The idea that there is a 'requirement' for degradable protein is therefore not an unreasonable one. The results of a series of subsequent experiments were consistent with the idea that cows, given a choice between foods with different RDP contents, selected sufficient RDP and also avoided eating an excess (Tolkamp et $a l .1998 b$ ). These findings need to be reconciled with the results of other research in which ruminants seemed to be able to select a diet that reflected their protein needs according to their physiological state (Kyriazakis \& Oldham, 1993; Cooper et al. 1994; Kyriazakis et al. 1994). In the latter experiments there were differences between the diets used in both their calculated MP yields and in their
RDP contents, and it is not clear whether the diet selection observed in these experiments should be interpreted in terms of the MP or the RDP axis.

While we are continuing to test several hypotheses on the underlying causes of the observed selection of diets in ruminant animals, the results of the earlier experiments as a whole have led us to the idea of trade-offs in diet selection. The outcome of at least some of the previous experiments can be seen as the animal needing to trade-off between selecting a diet that meets its degradable protein requirements and one that avoids an excess intake of MP. The wider use of the idea of trade-offs in diet selection is discussed in the following section.

\section{The idea of trade-offs in diet selection}

We have argued that an animal has to consider the consequences of its feeding behaviour on its internal state before making a choice. In this section we use the idea that different choices will have different effects in terms of both benefits and costs. Where one choice has both higher benefits and higher costs than the other, then the animal has to make some trade-off between the increased benefit and the increased cost in order to come to a decision. The challenge is to express both benefits and costs in terms of the same currency. (In human decision making the usual first currency is money; when non-linearity, uncertainty and risk are introduced the currency becomes the vaguer 'utility'). If the animal is to make a choice, and it does have to, then in its own terms there must be a currency, or a scale, on which both benefits and costs can be assessed. It is then presumed to make the choice which either maximizes the difference between benefits and costs, or which gives the higher benefit: cost ratio; the debate continues as to which criterion is more relevant.

Earlier, we introduced a trade-off that seemed to apply in the diet selection of ruminant animals. They appeared to select a diet that met their RDP requirements even if this meant that excess MP was eaten. The costs that are associated with the consumption of excess protein were given little weight by the animal compared with the benefits of meeting the RDP requirement. Another example in which an animal may have to make a trade-off between alternatives is when it is given the opportunity to correct, through its diet selection, imbalances in its internal state that have been created by, for example, malnutrition. One expectation is that it would attempt to correct such imbalances and hence return to its appropriate state as soon as possible (Kyriazakis, 1997). However, by choosing a diet that allowed this correction the animal might be faced with other costs, such as those of dissipating extra heat to the environment or of coping with excess bulk intake. The diet selected by the animal will then be the outcome of the weighting that it gives to the relevant benefits and costs. It is in this way that we now view the outcome of the diet selection of young pigs following a period of feeding on a low-protein food (Kyriazakis \& Emmans, 1991).

It is also possible that changes in the animal's internal state, or in its environment, could alter the weighting given to the benefits and costs of particular diets. This situation would lead to the choices made in different circumstances 
being different (Hutchings et al. 1999). The implication is that we need to be able to quantify such modifications in the currencies if we are to use the idea of trade-offs to quantitatively predict the diet selection of animals.

We have found it very useful to view the diet selection of animals within the context of trade-offs. One of the attractions of the approach is that both environmental and social influences on diet selection can also be seen as changes in the currencies of benefits and costs, and hence in the net benefit of a given trade-off or choice. A trade-off results from the animal calculating either the difference between the benefits of selecting a diet appropriate to the internal state and the costs that arise from the environment, or the benefit: cost. Such costs include the consumption of toxins associated with foods (possibly including $\mathrm{O}_{2}$, as emphasized by Tolkamp \& Ketelaars, 1992), the exposure to cold and the intake of infective agents.

Conventionally, the trade-off framework has been used to account for the selection of diets from foods that differ in their nutrient and toxin concentrations (Belovsky \& Schmitz, 1994). We are also using it to consider the diet selected by herbivores from two swards that differ in their nutrient content, but also at the same time carry different numbers of infective stages of parasites (Hutchings et al. 1999). The idea of benefits and costs that are weighted in some way by the animal appears to be helpful in considering cases where it has to make some kind of trade-off in its selection of a diet.

\section{Timescales of diet selection}

What is the change in an animal's internal state that needs to occur before it reacts to the change through a modification of its diet selection? This question was dealt with earlier. It is repeated here because, in terms of time, we need to know how much time is needed for changes to occur that are detectable. In the previous section we argued that such changes need to be of sufficiently large magnitude to be detected by the animal, rather than the systemic short-term fluctuations that occur in its internal state during the day. This argument was based on the fact that the animal's physiological controls will not use these small fluctuations, even if detected, to inform diet choice. The question of the relevant timescale for the control of feeding behaviour, termed 'the time-window of feeding' by Collier \& Johnson (1990), has occupied the time and effort of a number of researchers. Whilst there is agreement that feeding behaviour and diet selection are very flexible in the shortterm, they do not appear to arrive at a consensus for the definition of 'long-term'. The meaning of 'long-term' is related to the time needed for the effects of incorrect choices to be detected.

The idea of physiological, or metabolic, time (Taylor, $1980 a, b)$ is useful here. The definition of metabolic time, T, is $\mathrm{T}=$ time $/ \mathrm{A}^{0.27}$, where $\mathrm{A}$ is mature size. For an animal where A is $700 \mathrm{~kg}$ (e.g. a cow), metabolic time is $700^{0 \cdot 27}: 7^{0 \cdot 27}$ times as long as that for an animal where $\mathrm{A}$ is $7 \mathrm{~kg}$ (e.g. a chicken). The value for $700^{0 \cdot 27}: 7^{0 \cdot 27}$ is about $3 \cdot 5$, which suggests that 1 week to a cow is about equivalent to $2 \mathrm{~d}$ to a chicken. To estimate the relevant relative timescale in this way is only a first step. Time for a $700 \mathrm{~kg}$ cow producing $40 \mathrm{~kg} \mathrm{milk/d}$ is not likely to have the same meaning as that for a cow of the same weight but not producing any milk. The consequences of errors in intake or diet selection are likely to show up faster for the highproducing animal. However, between animals of different mature sizes the idea of a timescale expressed as $\mathrm{T}$ will be useful as a starting point.

To illustrate the idea of control over different timescales we will use some data from a group of eight cows (Tolkamp \& Kyriazakis, 1997). In Fig. 2 the composition of the diet selected by these cows when offered access to two foods that differed in their protein content is considered over three timescales: $8 \mathrm{~h}$, daily and weekly. It can be seen that within the shortest timescale considered (Fig. 2(a)) there is a very large variation in diet selection, ranging
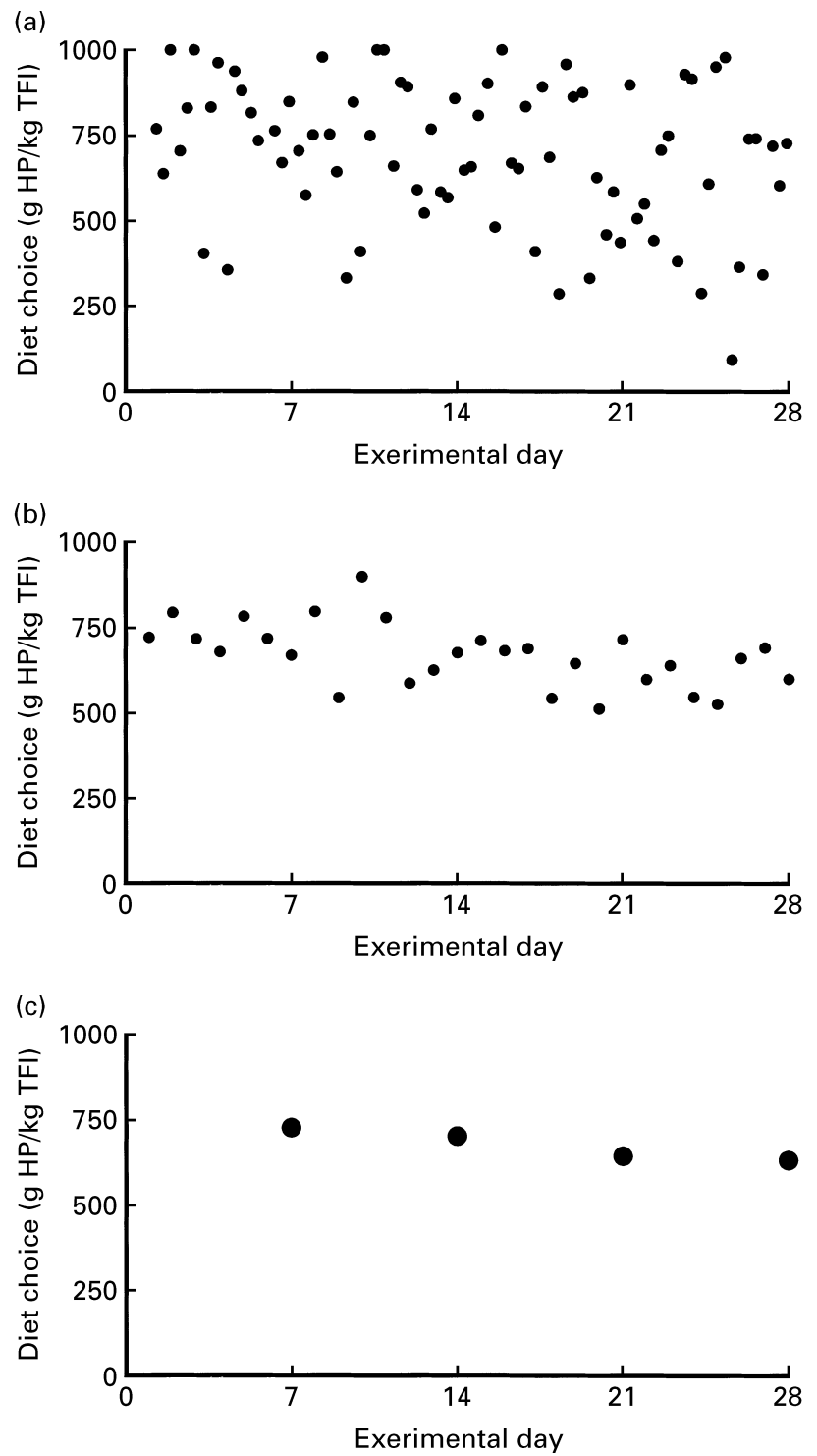

Fig. 2. The composition of diets selected by cows given access to two foods of different protein contents. The composition is expressed as $\mathrm{g}$ high-protein food (HP)/kg total food intake (TFI) and each point represents the mean for eight cows. Diet selection is shown for three time periods: (a) $8 \mathrm{~h}$ periods, (b) $24 \mathrm{~h}$ periods and (c) weekly. (From Tolkamp \& Kyriazakis, 1997.) 
from 100 to $1000 \mathrm{~g}$ high-protein food $/ \mathrm{kg}$ total food intake. When diet selection is considered in the 'medium' timescale of $1 \mathrm{~d}$ the variation is considerably reduced, but it still varies between 500 and $950 \mathrm{~g}$ high-protein food $/ \mathrm{kg}$ total food intake (Fig. 2(b)). It is only when diet selection is considered weekly that it appears to be systematic or regulated (Fig. 2(c)). From this experiment one can conclude that lactating cows regulate their diet selection using a timescale of between 1 and $7 \mathrm{~d}$. There are, however, other experiments on lactating cows in which diet selection appears to be regulated within a much shorter timescale (Fig. 3). In the latter experiment the change in diet selection of cows in response to a change in foods was very rapid. Within $1 \mathrm{~d}$ a preference for a high-protein food was changed towards a preference for a low-protein food by adding a source of degradable protein (urea) to both foods offered as a choice. The fact that the animals responded within $1 \mathrm{~d}$ to the change in the composition of their foods, but their response appears to be gradual in Fig. 3, is an experimental artifact. This artifact was created by the lower availability of the low-protein food in the latter part of the first day, as we had not anticipated such a swift change in diet selection. The difference between the two experiments can be explained in part by the difference in time needed for any errors in diet selection to be detected. In the second case errors would have led to large changes in rumen $\mathrm{NH}_{3}$ levels over very short periods of time.

Similar results are found in sheep. Young growing sheep appear to regulate the protein content of their diet within a timescale of about 3-7 d (Kyriazakis et al. 1994). However, they respond to a change in their rumen environment, as a consequence of feeding on a rapidly-fermentable food, by altering their diet selection within a few hours (James \& Kyriazakis, 1999). It seems to us, therefore, that the question to be asked in relation to diet selection is not "what time period matters to the animal?' but 'how much change or deviation in the internal state is the animal prepared to accept?' The latter question will be the focus of our research in the future.

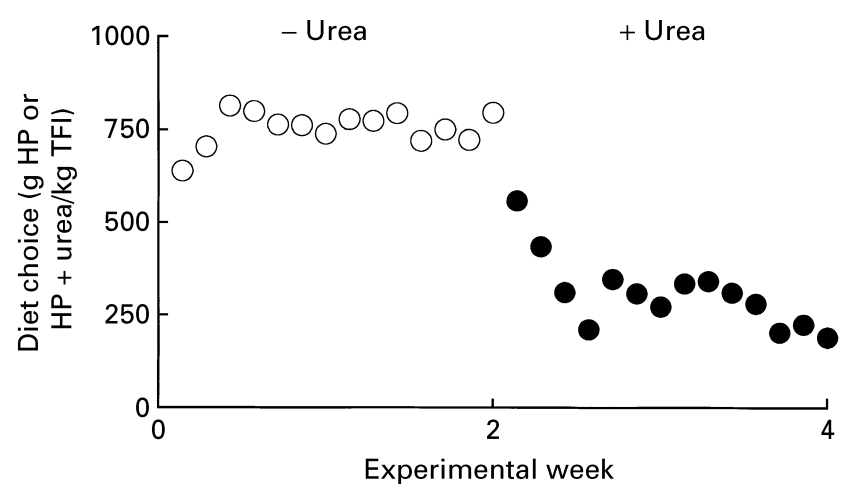

Fig. 3. The composition of diets selected by cows given access to two foods of different protein contents. In weeks 1 and 2 the basal foods were used and in weeks 3 and 4 both foods were supplemented with the same amount of urea. The composition is expressed as $\mathrm{g}$ high-protein food with $(\mathbf{0})$ or without $(\bigcirc)$ urea $(\mathrm{HP}) / \mathrm{kg}$ total food intake (TFI). Each point represents $1 \mathrm{~d}$ and is the mean for nine cows. (From Tolkamp et al. 1998b).

\section{Conclusions}

In the present paper we have dealt with the problems of explaining and predicting diet selection of animals under controlled conditions, in which conditions can be described and any influences of the environment can be either controlled or at least monitored. Diet selection was considered within a framework of feeding behaviour that views both food intake and diet selection as an outcome of the animal's internal state and knowledge of the feeding environment. Three questions that arise from the framework were considered here. First, how do animals learn about the foods available to them as a choice? Second, what changes in internal state affect diet selection? Third, how much time is needed for a change in the animal's internal state to be detected and for it to react to this change through a modification of its diet selection? It was concluded that animals have developed behavioural mechanisms that allow them to recognize foods on the basis of their nutritional as well as other properties. The rate at which animals learn about foods, and for how long this knowledge is retained, depends largely on the extent of the animal's deficiency and on the extent of the post-ingestive consequences induced by the foods. There is little evidence that animals modify their diet selection in response to the very short-term systemic fluctuation of their internal environment. On the other hand, long-term changes in the internal state of the animal lead to consequent longterm changes in their diet selection. The time needed for a change in diet selection to be observed seems to be dependent on the deviation created in the animal's internal state, either as a result of a physiological change or as a consequence of feeding. Thus, a more appropriate question to consider in relation to diet selection is not 'what time period matters to the animal?' but 'how much change or deviation in the internal state is the animal prepared to accept?'

\section{References}

Arsenos G \& Kyriazakis I (1999) The continuum between preferences and aversions for flavoured foods in sheep conditioned with administration of casein doses. Animal Science 68, 605-616.

Belovsky GE \& Schmitz OJ (1994) Plant defences and optimal foraging by mammalian herbivores. Journal of Mammalogy $\mathbf{7 5}$, 816-832.

Blair-West JR, Denton DA, McKinley MJ, Rodden BG, Ramshaw EH \& Wark JD (1992) Behavioural and tissue responses to severe phosphorus depletion in cattle. American Journal of Physiology 263, R656-R663.

Bradford MMV \& Gous RM (1991) The response of growing pigs to a choice of diets differing in protein content. Animal Production 52, 185-192.

Capaldi ED, Sheffer J \& Owens J (1991) Food deprivation and conditioned flavor preferences based on sweetened and unsweetened foods. Animal Learning and Behavior 19, 361-368.

Classen HL \& Scott TA (1982) Self-selection of calcium during the rearing and early laying periods of White Leghorn pullets. Poultry Science 61, 2065-2074.

Collier MJ \& Johnson DF (1990) The time window of feeding. Physiology and Behavior 48, 771-777. 
Cooper SDB, Kyriazakis I \& Oldham JD (1994) The effect of late pregnancy on the diet selection made by ewes. Livestock Production Science 40, 263-275.

de Jong A (1981) Short- and long-term effects of eating on blood composition in free-feeding goats. Journal of Agricultural Science, Cambridge 96, 657-668.

Denton DA (1982) The Hunger for Salt - An Anthropological, Physiological and Medical Analysis. Berlin: Springer-Verlag.

Deutsch JA, Moore BO \& Heinrichs SC (1989) Unlearned specific appetite for protein. Physiology and Behavior 46, 619-624.

Emmans GC (1991) Diet selection by animals: theory and experimental design. Proceedings of the Nutrition Society 50, 59-64.

Forbes JM \& Kyriazakis I (1995) Food preferences in farm animals: why don't they always choose wisely? Proceedings of the Nutrition Society 55, 429-440.

Hughes BO (1979) Appetites for specific nutrients. In Food Intake Regulation in Poultry. Proceedings of the Fourteenth Poultry Science Symposium, pp. 141-169 [KN Boorman and BM Freeman, editors]. Edinburgh: British Poultry Science Ltd.

Hutchings MR, Kyriazakis I, Gordon IJ \& Jackson F (1999) Tradeoffs between nutrient intake and faecal avoidance in herbivore foraging decisions: the effect of animal parasitic status, level of feeding motivation and sward nitrogen content. Journal of Animal Ecology 68, 310-323.

James SM \& Kyriazakis I (1999) The effect of consumption of foods that differ in energy density and/or sodium bicarbonate supplementation on subsequent diet selection in sheep. Proceedings of the 115th Meeting of the British Society of Animal Science, p. 114. Edinburgh: British Society of Animal Science.

Kendrick KM (1992) Cognition. In Farm Animals and the Environment, pp. 209-231 [C Phillips and D Piggins, editors]. Oxford: $\mathrm{CAB}$ International.

Krebs JR \& McCleery H (1984) Optimisation in behavioural ecology. In Behavioural Ecology - An Evolutionary Approach, 2nd ed. [JR Krebs and NB Davies, editors]. Oxford: Blackwell.

Kyriazakis I (1997) The nutritional choice of farm animals: to eat or what to eat? In Animal Choices, pp. 55-65 [JM Forbes, TLJ Lawrence, RG Rodway and MA Varley, editors]. Edinburgh: British Society of Animal Science.

Kyriazakis I, Anderson DH \& Duncan AJ (1998) Conditioned food aversions in sheep: the relationship between the dose rate of a secondary plant compound and the acquisition and persistence of aversions. British Journal of Nutrition 79, 55-62.

Kyriazakis I \& Emmans GC (1991) Diet selection in pigs: choices made by growing pigs following a period of underfeeding with protein. Animal Production 52, 337-346.
Kyriazakis I \& Emmans GC (1992) The selection of a diet by growing pigs given choices between feeds different in their contents of protein and rapeseed meal. Appetite 19, 121-132.

Kyriazakis I, Emmans GC \& Taylor AJ (1993) A note on the diets selected by boars given a choice between two foods of different protein concentrations from 44 to $103 \mathrm{~kg}$ liveweights. Animal Production 54, 151-154.

Kyriazakis I \& Oldham JD (1993) Diet selection in sheep: the ability of growing lambs to select a diet that meets their crude protein requirements. British Journal of Nutrition 69, 617-629.

Kyriazakis I, Oldham JD, Coop RL \& Jackson F (1994) The effect of subclinical intestinal nematode infection on the diet selection of growing sheep. British Journal of Nutrition 72, 665-677.

Nielsen BL (1999) On the interpretation of feeding behaviour measures and the use of feeding rate as an indicator of social constraint. Applied Animal Behaviour Science 63, 79-91.

Provenza FD, Villalba JJ, Cheney CD \& Werner SJ (1998) Self-organization of foraging behaviour: from simplicity to complexity without goals. Nutrition Research Reviews 11, 199-222.

Ralphs MH \& Provenza FD (1999) Social facilitation and learned food aversion. Proceedings of the Nutrition Society 58, 813-820.

Shariatmadari F \& Forbes JM (1992) Feeding behaviour of broiler chickens offered a choice of high- and low-protein foods. Animal Production 54, 470 Abstr.

Siegel PB (1993) Behaviour-genetic analyses and poultry husbandry. Poultry Science 72, 1-6.

Simpson SJ \& Ludlow AR (1986) Why locusts start to feed, a comparison of causal factors. Animal Behaviour 34, 480-496.

Taylor St CS (1980a) Genetic size-scaling rules in animal growth. Animal Production 30, 161-165.

Taylor St CS (1980b) Genetic size-scaling rules in animal growth. Animal Production 30, 167-175.

Tolkamp BJ, Dewhurst RJ, Friggens NC, Kyriazakis I, Veerkamp RE \& Oldham JD (1998a) Diet choice in dairy cows. I. Selection for feed protein content during the first half of lactation. Journal of Dairy Science 81, 2557-2669.

Tolkamp BJ \& Ketelaars JJMH (1992) Toward a new theory of feed intake regulation in ruminants. 2. Costs and benefits of feed consumption: an optimisation approach. Livestock Production Science 30, 297-317.

Tolkamp BJ \& Kyriazakis I (1997) Measuring diet selection in dairy cows: effect of training on choice of dietary protein level. Animal Science 62, 197-207.

Tolkamp BJ, Kyriazakis I, Oldham JD, Lewis M, Dewhurst RJ \& Newbold JR (1998b) Diet choice in dairy cows. II. Selection for metabolisable or for ruminally degradable protein? Journal of Dairy Science 81, 2670-2680. 